\title{
Analysis of flow resistance in bundles of power plant condensers
}

\author{
Artur Rusowicz ${ }^{1}$, Jakub Kajurek ${ }^{1, *}$, and Kuat Baubekov ${ }^{2}$ \\ ${ }^{1}$ Warsaw University of Technology, Faculty of Power and Aeronautical Engineering Institute of Heat \\ Engineering, ul. Nowowiejska 21/25, 00-665 Warsaw, Poland \\ ${ }^{2}$ S.Seifullin Kazakh AgroTechnical University, Faculty of Power Engineering, Department of Heat \\ Power Engineering, Zhenis avenue 62, 010011 Astana, Republic of Kazakhstan,
}

\begin{abstract}
Shell-side pressure drop is a very important variable in the successful design of the condensers. The prediction of this pressure drop through the horizontal tube banks, with condensation, has long been a problem facing design engineers. Low pressure drop is a requirement in designing condensers for power plants. The paper presents a comparison of the various correlation to determine the pressure drop in the tube bundle. It is an important element for the verification of numerical simulations. Analysis of flow resistance for power plant condenser were made.
\end{abstract}

\section{Introduction}

A condenser is an important component that affects the efficiency and performance of power plants. Development of advanced numerical methods for shell-side flows in condensers is a critical step in improving current condenser design techniques. The advantage of numerical simulation is that they can provide a more detailed information on fluid flow and heat transfer in the tube bundle. This information may eliminate, in early stages of the design process, the problems related with flow induced vibration and flow distribution and improve overall heat transfer coefficients and increase the unit performance.

Numerical modelling of the power plant condensers play an important role in the design and the diagnosis of this type of heat exchangers [1-4]. The development of mathematical and physical models should be verified in the way of experiments [5,6]. Due to the significant size of these heat exchangers and an important role in the energy system access to this data is limited.

The shell-side and water-side flows are treated as the steady state and the steam-side flow is assumed to behave as an ideal mixture made up of noncondensable gases and steam only. The steam is taken as saturated. The mixture of noncondensable gases and steam assumed to be perfect gas, although other equations of state could be considered. The two-dimensional steady-state porous medium conservation equations of mass, momentum, heat and mass transfer resistance are written in Cartesian coordinate system. Local volume porosity $\beta$ is defined as ratio of the fluid volume and total volume of the corresponding element. Mass conservation equation for the mixture:

\footnotetext{
${ }^{*}$ Corresponding author: jakub.kajurek@itc.pw.edu.pl
} 


$$
\frac{\partial(\beta \rho u)}{\partial x}+\frac{\partial(\beta \rho v)}{\partial y}=-\beta \dot{m}
$$

Momentum conservation equations for the mixture:

$$
\begin{aligned}
& \frac{\partial}{\partial x}(\beta \rho u u)+\frac{\partial}{\partial y}(\beta \rho v u)=\frac{\partial}{\partial x}\left(\beta \mu_{e f f} \frac{\partial u}{\partial x}\right)+\frac{\partial}{\partial y}\left(\beta \mu_{e f f} \frac{\partial u}{\partial y}\right)-\beta \frac{\partial p}{\partial x}-\beta \dot{m} u-\beta F_{u} \\
& \frac{\partial}{\partial x}(\beta \rho u v)+\frac{\partial}{\partial y}(\beta \rho v v)=\frac{\partial}{\partial x}\left(\beta \mu_{e f f} \frac{\partial v}{\partial x}\right)+\frac{\partial}{\partial y}\left(\beta \mu_{e f f} \frac{\partial v}{\partial y}\right)-\beta \frac{\partial p}{\partial y}-\beta \dot{m} u-\beta F_{v}
\end{aligned}
$$

where $x$ is the longitudinal coordinate to the flow direction, $y$ is the perpendicular coordinate to flow direction, $u$ is the velocity in the $x$ direction, $v$ is the velocity in the $y$ direction, $\rho$ is the density, $p$ is the pressure, $\dot{m}$ is the mass flow rate, $\beta$ is the local porosity, $\mu_{e f f}$ is the effective viscosity, $F$ is the local flow resistance.

The boundary conditions for the inlet, vent, walls and baffles and plane of symmetry are:

- Inlet: The velocity and pressure are specified at inlet boundary.

- Walls: The shell walls and baffles of condenser are assumed to be nonslip, impervious to flow and adiabatic. Thus, the normal velocity components are equal to zero.

- Vent: At the outlet of the condenser, the boundary condition is velocity of steam-air mixture, which is calculated on the basis of the characteristic of venting apparatus.

- Plane of symmetry: Along the centre line the derivatives with respect to the cross-steam direction of all field variables are set to zero.

The mathematical model of the steam flow 1-3 and the heat transfer in the power plant condenser is solved. As a result of this solution the values of mixture velocity and pressure are obtained. The whole procedure is repeated until the satisfactory accuracy is achieved. For solving system eqs. (1)-(3) the Stream line Upwind Petrov-Galerkin finite element method is applied. The calculations are performed in mesh using of 852 points and 1542 triangles in the main and cross flow direction. The geometric and operating parameters for steam condenser are given in tab. 1.

In the description of the heat exchange in the energy condensers there are three driving forces: the temperature difference, the difference of gas concentrations and a decrease in a vapor pressure associated with a hydraulic flow resistance. Article focuses on the description of the hydraulic flow resistance in a bundle of energy condensers. It compares the several available correlations that can be used to verify the numeric calculations. The flow resistances are one of the components affecting the total pressure drop in tube bundle. The second important element is the establishment of conducting compressible fluid flow. The value of the effective viscosity is assumed in the calculations $\mu_{\text {eff }}$. The choice of this value also requires optimization as the literature gives different guidelines [7]. The article, however, focuses on the analysis of the flow resistance associated with the flow resistance forces. 
Table 1. Geometric and operating parameters for a $50 \mathrm{MWe}$ condenser.

\begin{tabular}{|c|c|}
\hline \multicolumn{2}{|c|}{ Geometrical parameters } \\
\hline Number of Tube Bundles & 7642 \\
\hline Number of Tubes Per I Bundle & 3812 \\
\hline Number of Tubes Per II Bundle & 3830 \\
\hline Condenser Length [m] & 6.58 \\
\hline Tube Outer Diameter [mm] & 24 \\
\hline Tube Inner Diameter [mm] & 22 \\
\hline Tube Pitch [mm] & 32 \\
\hline Tube material & Brass \\
\hline Operating parameters & 24 \\
\hline Inlet Temperature of Cooling Water $\left[{ }^{\circ} \mathrm{C}\right]$ & 1.57 \\
\hline Inlet Velocity of Cooling Water $[\mathrm{m} / \mathrm{s}]$ & 140 \\
\hline Total Steam Condensation Rate $[\mathrm{t} / \mathrm{h}]$ & \\
\hline
\end{tabular}

\section{Mathematical model}

The literature uses different coefficients describing the flow resistance in a bundle of tubes. The most common are used depending on where the pressure drop is proportional to the kinetic energy of flowing fluid. The dependences on local flow resistance in a bundle of pipes are widely used [8]:

$$
\begin{aligned}
& F_{u}=\xi \rho u U \\
& F_{v}=\xi \rho v U
\end{aligned}
$$

where $U$ is the resultant speed of the steam. The pressure loss factor can be determined based on the relationship proposed by Rhodesa and Carlucci [9]:

$$
\xi=2\left(\frac{f}{P}\right)\left(\frac{P \beta}{P-d_{o}}\right)^{2}\left(\frac{1-\beta}{1-\beta_{t}}\right)
$$

where $P$ is the tube pitch, $d_{o}$ is the tube outer diameter and $f$ is the coefficient of resistance expressed as:

$$
\begin{gathered}
f=0.619 R e^{-0.198} \text { for } \operatorname{Re}<8000 \\
f=1.156 R e^{-0.2647} \text { for } 8000 \leq \operatorname{Re}<200000
\end{gathered}
$$

The local porosity $\beta$ in Eq. (5) is defined as follows:

$$
\beta=1-\frac{N}{N_{t}}\left(1-\beta_{t}\right)
$$

where $N$ is the number of analysed tubes in a row, $N_{t}$ is the number of pipes in a row, $\beta_{t}$ is the porosity within the tube bundle.

An alternative approach to describe the flow resistance in a bundle of tubes is to use the same as for porous deposits, Darcy's law: 


$$
\begin{gathered}
F_{u}=\mu R_{u} u \\
F_{v}=\mu R_{v} v
\end{gathered}
$$

where the flow resistance $R_{u}$ and $R_{v}$ are specified with empirical dependencies [10]:

$$
\begin{aligned}
& R_{u}=d_{o}^{-2} G f \theta_{u} \\
& R_{v}=d_{o}^{-2} G f \theta_{v}
\end{aligned}
$$

$G$ in above equations is the coefficient, which depends on the geometry of the pipe bundle:

$$
G=-1.017+\frac{0.3325}{\beta}+\frac{0.3574}{\beta^{2}}+\frac{0.01348}{\beta^{3}} \text { for } \operatorname{Re}>20
$$

The resistance factor $f$ is given as:

$$
\begin{gathered}
f=350 R e^{0.0446} \text { for } R e<20 \\
f=103 R e^{0.338} \text { for } 20<\operatorname{Re}<300 \\
f=6.64 R e^{0.880} \text { for } \operatorname{Re}>300
\end{gathered}
$$

The local porosity in Eq. (13) for hexagonal pitch in bundle is specified as:

$$
\beta_{h}=1-\frac{\pi}{2 \sqrt{3}}\left(\frac{d_{o}}{P}\right)^{2}
$$

while for square pitch tubes as:

$$
\beta_{k}=1-\frac{\pi}{4}\left(\frac{d_{o}}{P}\right)^{2}
$$

In equations (11) and (12) $\theta_{u}$ and $\theta_{v}$ respectively are the correction factors that determine the condensation of steam i.e. effects of biphasic mixture on the flow resistance, which are the features of flow direction and the Reynolds number.

Based on experimental work in the Institute of Heat Engineering at Warsaw University of Technology flow resistance coefficients were proposed [11]:

- for a hexagonal bundle

$$
f=10.69 R e^{0.821} \text { for } 300<R e<8000
$$

- for a square bundle

$$
f=4 R e^{0.951} \text { for } 300<R e<8000
$$

- and from examination [10] for both types of bundle

$$
f=7.87 R e^{0.88} \text { for } 300<R e<8000
$$

The unit pressure drop was determined as: 


$$
\frac{\Delta p}{\Delta x}=\frac{\mu}{d_{o}^{2}} f U
$$

All above correlations are being used in two-dimensional calculations of energy condensers with isotropy assumption of oppositions of the flow in the bunch.

\section{Analysis of the results}

The calculations were carried out for the power plant condenser of the block $50 \mathrm{MW}$ built from brass pipes about the outer diameter of $24 \mathrm{~mm}$, wall thickness of $1 \mathrm{~mm}$ and for hexagonal scale of $32 \mathrm{~mm}$. The following parameters were taken: steam pressure at the inlet to the condenser of $7778 \mathrm{~Pa}$, temperature of the cooling water of $25^{\circ} \mathrm{C}$, steam speed at the inlet to the condenser of $37.4 \mathrm{~m} / \mathrm{s}$ and stream of steam of $140 \mathrm{t} / \mathrm{h}$ [6]. The cross section of the analysed condenser is described in Fig. 1a with emphasized A-A (hexagonal bunch of the pipes) and B-B (square bunch of the pipes) sections at which drops of the pressure were being analysed. The diameters were selected in a way allowing steam flow in vertical and horizontal direction in the bunch of pipes.

The pressure drops in the sections A-A and B-B were determined based on the numerical simulations with using correlation (9)-(12). Two different effective viscosities were used, which were equalled respectively to 100 and 1000 of the molecular viscosity. An average speed of the steam for section A-A was assumed to be $6 \mathrm{~m} / \mathrm{s}$, what corresponded to the individual drops of the pressure of $220 \mathrm{~Pa} / \mathrm{m}$ for $\mu_{\text {eff }}=100 \mu_{m o l}$ and of $333 \mathrm{~Pa} / \mathrm{m}$ for $\mu_{e f f}=1000 \mu_{m o l}$ (Fig. 1b). For section B-B the individual drops of the pressure for both effective viscosities at the average speed of the steam were equalled to $290 \mathrm{~Pa} / \mathrm{m}$.

a)

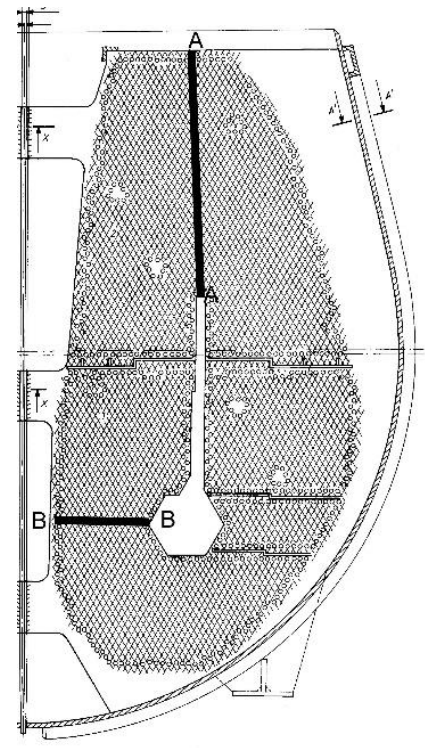

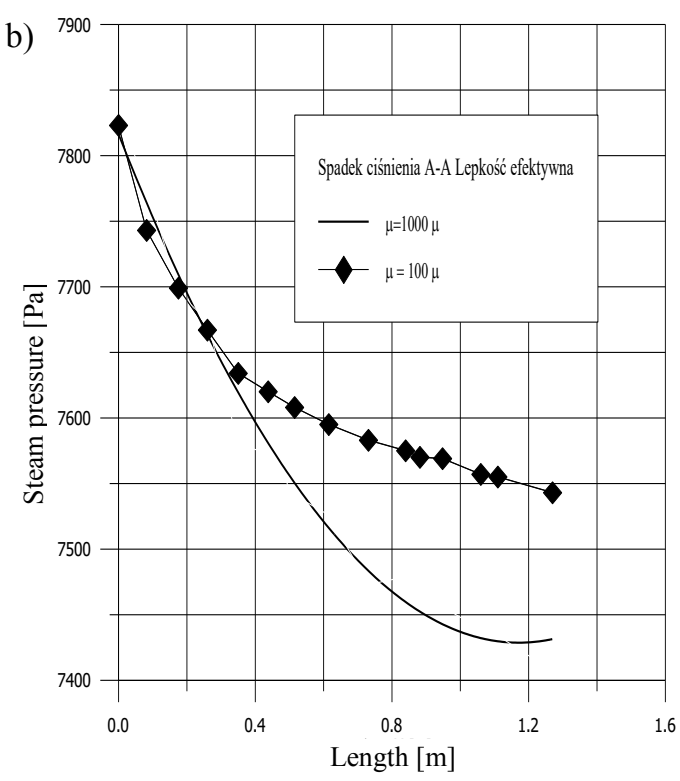

Fig. 1. a) cross-section of the condenser with sections A-A and B-B, b) pressure drops for section A-A.

The pressure drops calculated based on the correlations presented in section 2 are shown in Fig. 2. A good agreement between the numerical calculations with the empirical 
correlations can be observed. A pressure drops between 290-333 Pa/m for an average steam speed of $6 \mathrm{~m} / \mathrm{s}$ was achieved nearly for all correlations. Only the result from Rhodesa and Carlucci equations shows quite a deviation. The pressure drops described by the correlations are strongly affected by the effective viscosity. The effective viscosity can be optimized in relation to steam balances, what was proposed for example in [10]. As a part of conducted analysis, it can be also stated that the pressure drops for the hexagonal bunches are higher than for the square. These results are also in accordance with the experimental results presented in [12].

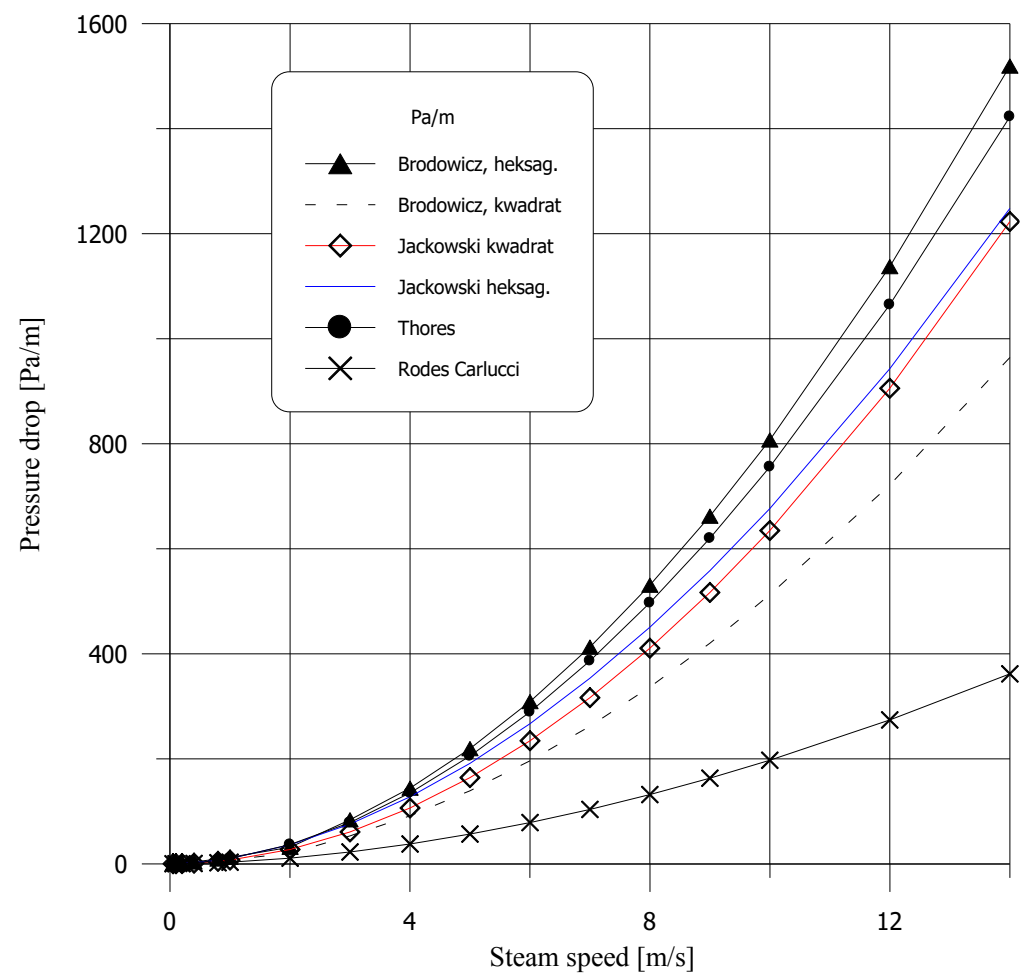

Fig. 4. The pressure drops obtained from different correlations.

\section{Conclusion}

In this paper the comparison of the various correlation for the pressure drop in the tube bundle is presented. The pressure drops were analysed for the hexagonal bunch of the pipes as well as for the square. The hexagonal arrangement was also analysed numerically. A good agreement between the results from numerical calculations and empirical correlations for the hexagonal bunch was achieved. It was also shown that the pressure drops for the hexagonal bunch are higher than for square.

\section{References}

1. R. Laskowski, A. Rusowicz, A. Grzebielec, Arch. Thermodyn. 36, 3 (2015)

2. R. Laskowski, A. Rusowicz, A. Grzebielec, Przem. Chemiczny 94, 10 (2015) 
3. R. Laskowski, A. Smyk A. Rusowicz, A. Grzebielec, Entropy 18, 12 (2016)

4. C. Zhang, A Bokil. Int. Journal of Heat and Mass Transfer 40, 15 (1997)

5. A. Rusowicz, A. Grzebielec, R. Laskowski, Rynek Energii 134, 1 (2018)

6. A. Rusowicz, R. Laskowski, A. Rusowicz, Thermal Science 21, 1A (2017)

7. K. Brodowicz, K. M. Ostrowski, A. Rusowicz, D. Wierzbicki, Biuletyn ITC PW 80, (1995)

8. T. Fujii, H. Uehara, K. Hirata, K. Oda, Int. Journal Heat Mass Transfer 15, 2 (1972)

9. B. D. Rhodes, L. N. Carlucci, Int. Conf. on Numerical Method in Nuclear Engineering, Canadian Nuclear Society/American Nuclear Society, Montreal (1983)

10. K. Brodowicz, A. Czaplicki, Int. Heat Transfere Conf., San Francisco (1986)

11. L. Jackowski, Dissertation, Institute of Heat Engineering, Warsaw University of Technology (1987)

12. N. E. Todres, D. Ebeling-Koning, J. T. Robnison, Report No DOE/ER/12075-4FR (1985) 